\title{
Compatibility of C- and Ku-band scatterometer winds: ERS-2 and QuikSCAT
}

\author{
Abderrahim Bentamy ${ }^{\mathrm{a}}$, Semyon A. Grodsky ${ }^{\mathrm{b},{ }^{*},}$, Bertrand Chapron ${ }^{\mathrm{a}}$, James A. Carton ${ }^{\mathrm{b}}$ \\ a Institut Francais pour la Recherche et l'Exploitation de la Mer, Plouzane, France \\ ${ }^{\mathrm{b}}$ Department of Atmospheric and Oceanic Science, University of Maryland, College Park, MD 20742, USA \\ *: Corresponding author : Semyon A. Grodsky, tel.: + 13014055330 ; fax: + 13013149482 ; \\ email address : senya@atmos.umd.edu
}

\begin{abstract}
:
Global winds provided by satellite scatterometry are an important aspect of the ocean observing system. Many applications require well-calibrated time series of winds over time periods spanned by multiple missions. But sensors on individual satellites differ, introducing differences in wind estimates. This study focuses on global winds from two scatterometers, ERS-2 (1996-2001) and QuikSCAT (1999-2009) that show persistent differences during their period of overlap (July-1999 to January 2001). We examine a set of collocated observations during this period to evaluate the causes of these differences. The use of different operating frequencies leads to differences that depend on rain rate, wind velocity, and SST. The enhanced sensitivity to rain rate of the higher frequency QuikSCAT is mitigated by a combined use of the standard rain flag and removing data for which the multidimensional rain probability is $>0.05$. Generally, ERS-2 wind speeds computed using the IFREMER CMODIFR2 geophysical model function (GMF) are lower than QuikSCAT winds by $0.6 \mathrm{~m} / \mathrm{s}$, but wind directions are consistent. This wind speed bias is reduced to $-0.2 \mathrm{~m} / \mathrm{s}$ after partial reprocessing of ERS-2 wind speed using Hersbach's (2010) new CMOD5.n GMF, without altering wind direction. An additional contributor to the difference in wind speed is the biases in the GMFs used in processing the two data sets and is empirically parameterized here as a function of ERS-2 wind speed and direction relative to the mid-beam azimuth. After applying the above corrections, QuikSCAT wind speed then remains systematically lower (by $0.5 \mathrm{~m} / \mathrm{s}$ ) than ERS-2 over regions of very cold $\mathrm{SST}<5^{\circ} \mathrm{C}$. This difference may result from temperature-dependence in the viscous damping of surface waves which has a stronger impact on shorter waves and thus preferentially affects QuikSCAT.
\end{abstract}

\section{Highlights}

CMODIFR2-based ERS-2 wind speed $\left(W_{E R S-2}\right)$ is biased low by $1 \mathrm{~m} / \mathrm{s}$. $W_{E R S-2}$ is partially reprocessed using CMOD5.n GMF and unchanged wind direction. The full reprocessing is recommended due to differences in ERS-2 beams calibration. The partially reprocessed $W_{E R S-2}$ fits QuikSCAT except over cold SST $<5^{\circ} \mathrm{C}$. Higher viscous wave dissipation at cold SST preferentially impacts shorter wavelength QuikSCAT.

Keywords: Scatterometer winds ; SST ; Inter-instrument bias 


\section{Introduction}

Only satellite sensors, particularly scatterometers, can provide global synoptic observations of surface winds. Yet, while many applications require well-calibrated time series of winds over time periods spanned by multiple scatterometer satellite missions, the sensors on individual satellites differ, introducing differences in the wind estimates (Bourassa et al., 2009). For the period from 1996 to the present, three successive scatterometer missions have been operated: the C-band Remote Sensing Satellite (ERS-2) (1996-January 2001) followed by the Ku-band QuikSCAT (mid-1999 to late-2009), and by the C-band Advanced SCATterometer (ASCAT) (2007-onward). Creating a well-calibrated time series from such a succession of individual sensor records requires accounting for changes in individual sensor biases, and this accounting is most necessary when the scatterometers operate in different frequency bands and operating modes (e.g. Bentamy et al., 2002, Bentamy et al., 2012 and Ebuchi et al., 2002). Bentamy et al. (2012) have exploited the existence of a time overlap between missions to connect the wind records for QuikSCAT and ASCAT. Here we use the same approach to address the connection between QuikSCAT and the earlier ERS2. The successful result of this calibration exercise would be a continuous record of calibrated scatterometer winds spanning the past 13 years.

Scatterometers are microwave radars that infer near-surface wind velocity from the strength of the normalized radar backscatter coefficients (NRCS, $\sigma^{0}$ ) measured at a variety of azimuth $(X)$ and incidence angles $(\theta)$. The ocean surface radar signal backscatter occurs primarily from centimeter-scale capillary/gravity waves (ripples), whose amplitude is in 
equilibrium with the local near-surface wind. At a given wind velocity, it also depends on other parameters governing ripple generation such as SST-dependent water viscosity and air density, $\rho_{a}$, (Donelan et al., 1987), as well as other environmental conditions such as sea state degree of development and/or surface current (e.g. Quilfen et al., 2001, 2004). In this study we express surface wind speed in terms of $10 \mathrm{~m}$ equivalent neutral wind $(W)$, which is then related to NRCS using an empirical Geophysical Model Function (GMF). Equivalent neutral wind is the wind speed that would be associated with the actual wind stress if the atmospheric boundary layer was neutrally stratified. GMFs used in current scatterometer wind products do not include SST-dependence nor sea-state degree of development information.

Because of the need by many applications for a consistent, well-calibrated wind record there have been a number of previous efforts to combine wind records from these scatterometer missions. Generally these efforts have taken the approach of relating each mission wind time series to a reference wind field spanning all missions that is itself assumed to be consistent and well-calibrated. Such efforts have used both passive microwave winds and reanalysis winds for this referencing (e.g. Wentz et al, 2007; Bentamy et al., 2007; Atlas et al., 2011). The disadvantages of this approach lie in the assumption that the reference wind field is itself well-calibrated, and in the fact that the corrections that are made to the scatterometer mission winds are unrelated to the basic physical variables being measured (e.g., $\sigma^{0}, \theta, \chi$ ). Use of reanalysis winds for referencing is particularly troubling if the reanalysis winds assimilate the same scatterometer winds that they are then compared to.

\section{Data}

In this section we provide a brief description of the ERS-2 and QuikSCAT data sets. Additional details are provided in the corresponding user manuals (CERSAT, 1994; and JPL, 2006). Radar microwaves from C-band ERS-2 (5.3GHz) / Ku-band QuikSCAT (13.4GHz) 
scatter most efficiently from short scale waves with about $5 \mathrm{~cm} / 2 \mathrm{~cm}$ lengths, respectively, a phenomenon known as the Bragg scattering.

\subsection{ERS-2}

The active microwave instrument on board ERS-2 is the same C-band (5.3 GHz, 5.7 cm) scatterometer as onboard ERS-1. It operated from April 21, 1995 through September 5, 2011. However, due to the on-board recorder failure, global data are available only through early January 2001. The scatterometer has three antennae looking $45^{\circ}$ forward (fore-beam), perpendicular (mid-beam), and $45^{\circ}$ backward (aft-beam) relative to the satellite track and illuminating a $500 \mathrm{~km}$ wide swath to the right of the satellite track. 10 m equivalent neutral wind speed and direction are inferred at 50km spatial resolution using the Center for Satellite Exploitation and Research (CERSAT) GMF (Quilfen et al., 1995) based on the Institut Français de Recherche pour l'exploitation de la Mer (IFREMER) version 2 GMF (CMODIFR2 of Bentamy et al., 1999). CMODIFR2 was derived by fitting ERS-1 winds to collocated National Data Buoy Center (NDBC) buoy winds. CMODIFR2 has been applied to ERS-2 without any adjustments. Land, ice, and rain contaminations are excluded using the CERSAT quality flags. Although this version of the ERS-2 winds is known for persistent wind speed underestimation at $W>5 \mathrm{~m} / \mathrm{s}$ and a rare occurrence of low wind data (Bentamy et al., 2002), it is the only one spanning the entire mission in the global domain.

\subsection{QuikSCAT}

The SeaWinds Ku-band (13.4 GHz, $2.2 \mathrm{~cm})$ scatterometer onboard the NASA/QuikSCAT (referred to subsequently as QuikSCAT or QS) was launched in June 1999. The QuikSCAT rotating antenna has two emitters: the H-pol inner beam at $\theta=46.25^{\circ}$ and V-pol outer beam at $\theta=54^{\circ}$ with swath widths of $1400 \mathrm{~km}$ and $1800 \mathrm{~km}$, that together cover around $90 \%$ of the global ocean daily. QuikSCAT swath data is binned into wind vector cells of $25 \times 25 \mathrm{~km}^{2}$. QuikSCAT winds used here are Level $2 \mathrm{~b}$ data, derived from backscatter 
using the empirical QSCAT-1 GMF (JPL, 2006) together with a Maximum Likelihood Estimator, which selects the most probable wind solution. To improve wind direction in the middle of swath where the azimuth diversity is poor, the Direction Interval Retrieval with Threshold Nudging algorithm is applied. This retrieval technique provides approximately 1 $\mathrm{m} / \mathrm{s}$ and $20^{\circ}$ accuracy in wind speed and direction, respectively (e.g. Bentamy et al., 2002, Bourassa et al., 2003, Ebuchi et al., 2002).

Due to its shorter wavelength Ku-band scatterometers are more sensitive to impacts of rain than longer wavelength C-band scatterometers. Rain perturbations result from attenuation by raindrops in the atmosphere as well as amplification due to volume scattering and changes of sea surface roughness by impinging drops (Tournadre and Quilfen, 2003, 2005). It is observed (Weissman et al., 2002) that the amplification effects dominate and impact of undetected rainfall on the higher frequency QuikSCAT is to enhance backscatter leading to positive biases in $W_{Q S}$ of up to $1 \mathrm{~ms}^{-1}$ in the rainy tropical convergence zones and western boundary current regions even after rain flagging is applied (Bentamy et al., 2012). Two rain indices, rain flag and multidimensional rain probability (MRP), are provided with the QuikSCAT data set to mark heavy rainfall. QuikSCAT wind overestimation in tropics is reduced by some $30 \%$ to $40 \%$ when data for which MRP $>0.05$ are also removed. This combination of rain selection indices is thus applied to all QuikSCAT data in the rest of this study.

The shorter wavelength Ku-band radar is also more sensitive to the direct impact of SST, which at a given value of wind speed, alters the amplitude of the surface ripples through the competing effects of $\rho_{a}$-dependent wind wave growth rate and SST-dependent viscous wave dissipation (Donelan et al., 1987; Grodsky et al., 2012). 


\subsection{Collocated data}

The procedure we use to identify collocations of ERS-2/QuikSCAT observations is similar to that described in Bentamy et al. (2012). The period of overlap when both ERS-2 and QuikSCAT provide global ocean coverage extends from July 1999 to January 2001. During this period we identify all pairs of observations where the spatial separation between collocated ERS-2 and QuikSCAT cells is less than $50 \mathrm{~km}$. The two satellites are on quasi sunsynchronous orbits, but the QuikSCAT local equator crossing time for ascending tracks (6:30 a.m.) leads the ERS-2 local equator crossing time (10:30 a.m.) by approximately 4 hours. This implies that spatial collocations of the two instruments occur with a minimum time difference of a few hours at low latitudes. If we accept pairs of observations also with a temporal separation $\tau$ of less than 5 hours then the resulting spatial coverage of these points is global, with $>36$ million collocations, but with the majority of the collocations at higher latitudes due to the polar convergence of the orbits (Bentamy et al., 2012).

In addition to compare ERS-2 and QuikSCAT we are interested in connecting each to ground observations. Thus ERS-2 and QuikSCAT winds (within 50km and 1hour for ERS-2 and $25 \mathrm{~km}$ and 30min for QuikSCAT) are also separately compared to the NDBC moored buoys, and the Tropical Atmosphere Ocean Project (TAO) and Pilot Research Moored Array (PIRATA) moorings. Hourly averaged buoy wind velocity, SST, air temperature, and humidity are converted to $10 \mathrm{~m}$ equivalent neutral wind using the COARE3.0 algorithm of Fairall et al. (2003). Details of the buoy instrumentation are provided in Meindl et al. (1992), McPhaden et al. (1998), and Bourles et al. (2008).

\section{ERS-2 wind accuracy}

Our initial comparison of ERS-2 wind speed based on the CMODIFR2 GMF shows ERS-2 winds to be biased low for winds $<13 \mathrm{~m} / \mathrm{s}$ in comparison with in-situ winds (Fig. 1a), as has been previously shown by Bentamy et al. (2002). At higher winds the satellite wind speed 
may be biased high, but this conclusion is uncertain due to the rarity of high wind conditions. The satellite-derived wind direction is consistent with in-situ wind direction to within $10^{\circ}$ without evidence of bias (Fig. 1b).

Table 1 presents satellite-buoy comparison statistics based on collocated buoy and satellite data with valid quality control flags. In particular, QuikSCAT data is selected based on both the rain flag and $\mathrm{MRP}<0.05$, as explained in Bentamy et al. (2012). One should notice wind direction agreement is defined as vector correlation, and thus varying between -2 and +2 (Crosby et al., 1993). The results show ERS-2 wind speed to be biased low by $0.6 \mathrm{~m} / \mathrm{s}$ while the QuikSCAT wind speed bias is negligible. Wind direction from both scatterometers compares well with buoy wind direction (see also Fig.1b). Statistical comparisons of buoysatellite winds based on the entire period for each mission (March 1996 - January 2001 for ERS-2, and July 1999 - November 2009 for QuikSCAT) are in line with those based on the shorter period of overlap (July 1999 - January 2001). This agreement illustrates the representativeness of the common period, which is used for collocated data. Similarity of buoy-ERS/2 and QuikSCAT-ERS/2 wind speed differences also suggests that CMODIFR2based ERS/2 wind speed is biased low.

The ERS-2 wind speed underestimation seen in the previous comparisons with the buoys (Fig. 1a) is also present in the global ERS-2/QuikSCAT comparison (Fig. 2a). But, like the buoy comparisons, the wind direction from the two missions is consistent (Fig. 2b). Time mean ERS-2 wind speed is lower than QuikSCAT wind speed almost everywhere (Fig. 3a) except at high latitudes where the differences are reduced. However, the improved agreement at high latitudes results from ERS-2 bias and QuikSCAT bias compensation, which is tentatively explained by a regional negative bias in QuikSCAT winds due to unaccounted for stronger viscous dissipation of the Bragg waves in cold water (Bentamy et al., 2012; Grodsky et al., 2012). 
The temporal variability of ERS-2 and QuikSCAT winds is consistent with correlations exceeding 0.8 at most locations except low latitudes (Fig. 3c). The reduced correlation and stripes of increased STD at low latitudes follow major tropical precipitation zones (Figs. 3b, 3c) and are likely the result of the presence of short-lived convective variability and related rainfall, which causes differences in the conditions viewed by the two satellites because of their temporal separation of up to 5 hours. Furthermore, some rain events may not be detected by standard algorithms (Tournadre and Quilfen., 2003, 2005) causing an increase of difference between the scatterometer retrievals, especially in the tropics. Away from the tropics, the STD between collocated wind speeds (Fig. 3b) significantly increases in the midlatitude storm track bands likely reflecting the impact of synoptic events.

The ERS-2 wind bias may have at least two causes: (i) uncertainties in backscatter coefficient calibration and (ii) uncertainties in GMF parameterization. To the best of our knowledge only a $0.165 \mathrm{~dB}$ bias in the calibrated backscatter coefficients has been previously reported (Crapolicchio et al., 2007). We shall further discuss (i) in the Discussion section. (ii) Some impact due to GMF uncertainty is to be expected because, as noted above, the GMF CMODIFR2 was developed for ERS-1, but applied to ERS-2 without any adjustments.

Since the original processing of ERS-2 global winds by IFREMER, a number of C-band GMFs have been specifically designed for ERS-2 backscatter. The latest, CMOD5.n, has been derived by Hersbach et al. (2007) using collocated ERS-2 $\sigma^{\circ}$ triplets and ECMWF shortrange forecast winds. Unfortunately no ERS-2 retrievals estimated from CMOD5.n are yet available during the period of interest (1996 - 2001). To compensate, we use a simple method to reduce the wind speed bias in the ERS-2 winds by applying CMOD5.n assuming that the wind direction determined using CMODIFR2 is bias-free (Figs. 1b, 2b, and Table 1). This wind direction assumption significantly simplifies and speeds up computing CMOD5.n winds. It is constructed from ERS-2 winds by adjusting the winds to minimize a cost function 
expressing the mean square difference between observed $\left(\sigma^{0}\right)$ and simulated $\left(\sigma_{\text {CMOD5.n }}^{0}\right)$ backscatter coefficients, following Quilfen (1995):

$$
J(W, \chi)=\sum_{i=1}^{3}\left[\sigma_{i}{ }^{0}-\sigma_{i}{ }^{0} \text { СMOD5.n }(W, \chi)\right]^{2},
$$

Here $W$ is the new wind speed, $\chi$ is the wind direction relative to antenna azimuth (known from the winds produced using CMODIF2). At each ERS-2 Wind Vector Cell, ERS-2 wind speed based on CMOD2IFR is used as the first guess for minimization of (1). The resulting partial reprocessing of ERS-2 wind speed produced in this study is available only for the collocated data and is referred to as the new ERS, or ERS/N winds.

Reduction in the ERS/N wind speed bias in comparison with the original CMOD2IFRbased data is seen in the reduced difference of generally less than $0.1 \mathrm{~m} / \mathrm{s}$ with respect to NDBC wind speeds (Table1) and in comparison with QuikSCAT (Figs. 3a, 4a). But, large discrepancies are still present along the North Atlantic and Pacific storm tracks, which may be related to the high variability and thus large errors resulting from sampling synoptic events. Errors are also noticeable in coastal areas where diurnal breezes are also poorly sampled in the collocated data (Bentamy et al., 2012).

Although the global mean wind speed difference between QuikSCAT and ERS-2 is reduced to about $-0.2 \mathrm{~m} / \mathrm{s}$ for ERS/N in comparison with about $0.6 \mathrm{~m} / \mathrm{s}$ for the original CMODIFR2-based winds (Fig. 5b), the negative difference becomes stronger over cold SST (Figs. 3a and 4a). But as noted earlier, the original weak wind speed difference at high latitudes (Fig. 3a) is due to compensating errors. At those latitudes, the global underestimation of CMODIFR2-based ERS-2 winds compensates for the local underestimation of Ku-band QuikSCAT winds over cold SST, thus leading to locally weak difference between the two retrievals. The partially reprocessed CMOD5.n-based winds (ERS/N) more closely agree with QuikSCAT (Fig. 4a), except at high latitudes where the difference between QuikSCAT and 
ERS/N wind speed is of the same order as that for QuikSCAT and ASCAT (Bentamy et al, 2012). Because both ERS-2 and ASCAT are C-band radars, the similarity of the two wind speed differences at high latitudes underlines the fact that this difference is due to the physics of radar backscattering and may be SST-dependent (see also Grodsky et al., 2012 for a model consideration of the effect).

\section{Adjusting ERS/N and QuikSCAT winds}

The zonally averaged difference between QuikSCAT and ERS/N wind speed of about $0.2 \mathrm{~m} / \mathrm{s}$ (Fig. 5b) includes biases due to inconsistencies in the retrieval procedures (GMFrelated bias) and due to frequency-dependence in the physics of wind inference.

\subsection{GMF related bias}

A difference in measuring geometry and retrieval procedures for the two scatterometers leads to a difference in wind speed $(W)$ due to biases in the GMFs used in processing the two data sets. Following Bentamy et al. (2012) a GMF-related correction ( $\Delta W 1$ ) is parameterized as a function of ERS/ $\mathrm{N}$ wind speed and direction relative to the mid-beam azimuth. The CMOD5.n GMF is parameterized by a truncated Fourier series of wind direction relative to antenna azimuth, $\chi$, with coefficients depending on wind speed and incidence angle, $\theta$. Due to the fixed orientation of the three beam observation geometry of ERS-2, only the wind direction relative to mid-beam azimuth is considered for the analysis of $\Delta W 1$. As previously found in the Bentamy et al. (2012) comparison of ASCAT and QuikSCAT winds, there is only a minor dependence of $\Delta W 1$ on $\theta$ (not shown). Together these observations suggest that the correction $\Delta W 1$ is a function of two variables: $W_{E R S / N}$ and $\chi$.

The construction of $\Delta W 1$ (Fig. 5a) begins by binning collocated differences $W_{Q S}-W_{E R S / N}$ as a function of $W_{E R S / N}$ and $\chi$ at latitudes equatorward of $50^{\circ}$ (where the negative SST-related bias is not dominant) (Fig. 4a). These binned differences have positive values for $W_{E R S / N}<5 \mathrm{~ms}^{-1}$ (not shown), which result from the one-sided distribution of wind 
speeds for winds approaching the low wind speed cutoff and thus should not be reflected in $\Delta W 1$ (Freilich, 1997). Artificially positive values at low winds are corrected for by multiplying the binned differences by a cut-off function, $\tanh \left[\left(W_{E R S / N} / 5\right)^{4}\right]^{1}$, the result of which we again call $\Delta W 1$. To mitigate the impact of sampling errors, we use bins containing at least 50 samples, then we smooth $\Delta W 1$ by the triangular $3 x 3$ spatial filter, and retain only the first 5 angular harmonics (Fig. 6a). ERS/N wind speed is lower than QuikSCAT wind speed for $W_{E R S / N}>15 \mathrm{~ms}^{-1}$ in the up- and down-wind directions (Fig. 6a), but the difference is opposite in the two cross-wind directions. The azimuth asymmetry of $\Delta W 1$ is unexpected because CMOD5.n itself has this symmetry. This suggests the presence of inconsistency in antenna calibration of the fore- and after-beams (discussed later).

The time mean spatial pattern of $\Delta W 1$ depends on the distribution of local wind speed and direction. Adding the $\Delta W 1$ correction to ERS/N wind speed, $W_{E R S / N}+\Delta W 1$, results in slight strengthening of the trade winds and weakening of the midlatitude westerlies (Fig. 7a). This correction reduces the global wind speed bias from $-0.2 \mathrm{~m} / \mathrm{s}$ to $-0.1 \mathrm{~m} / \mathrm{s}$ and improves the consistency of the corrected ERS/N and QuikSCAT winds at high latitudes (Figs. 4a,b and $5 a)$.

\section{2 SST-related bias}

After applying the GMF-related correction $\Delta W 1$, QuikSCAT wind speed remains systematically lower (by $0.5 \mathrm{~ms}^{-1}$, Fig. 4b) than corrected ERS/N wind speed mostly over regions of very cold SST $<5^{\circ} \mathrm{C}$. Modeling of this SST-related bias suggests that it is weak in the C-band and has a greater impact on shorter waves and thus preferentially impacts

${ }^{1}$ The low wind cut-off function we have chosen is somewhat arbitrary. It is used to ensure the GMF-related correction approaches zero at weak winds. The relative number of collocations at $W_{E R S}<5 \mathrm{~ms}^{-1}$ is very low because of the lack of low wind speeds in ERS-2 data. This prevents us from developing a more justifiable cut-off function. 
QuikSCAT, for which the major impact is due to the temperature-dependence of viscous dissipation of wind ripples (Grodsky et al., 2012). Differences tend to be more pronounced at high southern than northern latitudes due to the yearly distribution of low $\mathrm{SST}<5^{\circ} \mathrm{C}$ in each area (Bentamy et al., 2012).

Here we apply the Bentamy et al. (2012) estimate of the SST-related bias ( $\Delta W 2$, Fig. 6b) and subtract it from the QuikSCAT wind speed, $W_{Q S}-\Delta W 2$. Tabular values of $\triangle W 2$ as a function of wind speed and SST bins are adopted from Bentamy et al. (2012) (see their Fig. $11 \mathrm{~b}$ and sections 4.3). This correction increases $W_{Q S}$ over regions of cold SST (Fig. 7b) and eliminates much of the wind speed difference between QuikSCAT and corrected ERS/N winds at high latitudes (compare Figs. 4b and 4c), thus reducing the global-time mean difference to $0.01 \mathrm{~m} / \mathrm{s}$ (Fig. 5b). A slight improvement occurs in comparisons of NDBC buoy and SST-corrected QuikSCAT winds. Using only buoys moored offshore and north of $55^{\circ} \mathrm{N}$, the time mean difference of $W_{N D B C}-W_{Q S}$ is $0.11 \mathrm{~m} / \mathrm{s}$ while $W_{N D B C}-\left(W_{Q S}-\Delta W 2\right)$ is about $0.01 \mathrm{~m} / \mathrm{s}$. The SST-related correction is small at these locations. In fact, it becomes noticeable only at very low SSTs $<5^{\circ} \mathrm{C}$ (Fig. 6b), which are not common at NDBC locations.

\section{Discussion}

Bentamy et al. (2012) have shown that the overestimation of C-band scatterometer winds for crosswind directions is related to the inaccuracy of CMOD5.n in this direction. However, the difference ( $W_{Q S}-W_{E R S / N}$, Fig. 6a) is not symmetric in azimuth. ERS/N wind speed overestimation ( $W_{Q S}-W_{E R S / N}<0$ ) is more pronounced, up to $1 \mathrm{~m} / \mathrm{s}$, for the wind direction of $-90^{\circ}$ (clockwise from the mid-beam) than that for $+90^{\circ}$ where the difference is quite low. Similar angular behavior is found for NDBC buoy minus ERS/N wind speed binned as a function of wind direction (not shown). Although explanation of the asymmetry is still not clear, it may be a consequence of inconsistency in the ERS-2 beams inter-calibration. 
In an effort to understand the directional dependence of the wind speed differences between

QuikSCAT and ERS-2, we compare observed $\left(\sigma^{0}\right)$ and simulated $\left(\sigma_{C M O D 5 . n}^{0}\right)$ NRCSs for each

ERS-2 beam. Fig. 8 shows the differences $\left(\sigma^{0}-\sigma_{\text {CMOD5.n }}^{0}\right)$ evaluated for ERS-2 mid-beam

(dashed), fore-beam (solid), and aft-beam (open circle) as a function of the associated

differences are evaluated for the same surface wind using the same GMF. However, $\sigma^{0}-\sigma_{\text {CMOD5.n }}^{0}$ for fore-beam and that for aft-beam differ by about $0.1 \mathrm{~dB}$. Such a discrepancy between observed and simulated NRCSs for outer beams may lead to the azimuth asymmetry seen in Fig. 6a. These results agree with De Charia et al. (2009) and suggest the need for complete reprocessing of ERS-2 scatterometer backscatter coefficients and winds.

\section{Conclusion}

This study represents a continuation of the work of Bentamy et al. (2012) in constructing a consistent scatterometer time series spanning 1996-present despite changes in scatterometer technology. Whereas Bentamy et al. (2012) have compared Ku-band QuikSCAT and C-band ASCAT data, this study focuses on comparisons of QuikSCAT and C-band ERS-2 scatterometer winds. Following Bentamy et al. (2012) we identify collocated pairs of observations from the two missions during the 18 month period of mission overlap (July 1999-early January 2001), each separated by less than 5hr and 50km. Examination of the differences of these collocated pairs as well as comparisons the ground truth data from buoys reveals systematic biases in the $10 \mathrm{~m}$ equivalent neutral satellite wind speed (but not in wind direction) that are a function of radar azimuth angle and wind speed ranges, as well as SST and rainfall. In particular, undetected rainfall preferentially affects the higher frequency 
QuikSCAT by increasing the strength of backscatter, and thus the apparent wind speed. This error is reduced by complementing rain selection based on the standard QuikSCAT rain flag with excluding observations for which the multidimensional rain probability, MRP $>0.05$.

The currently available ERS-2 surface wind product that spans the entire mission with global coverage uses the IFREMER version 2 geophysical model function CMODIFR2 to convert normalized backscatter to surface winds. Winds based on this GMF (derived for the earlier ERS-1 mission) underestimate speed by $0.6 \mathrm{~m} / \mathrm{s}$ in comparison with QuikSCAT, although the directions are consistent. In contrast, Hersbach (2010) has shown that the new CMOD5.n GMF leads to much reduced bias in the wind estimates. Thus our first step is to introduce CMOD5.n as a modification of the current global ERS-2 surface wind product by assuming that wind direction remains unchanged, resulting in a modified surface wind product we call ERS/N, which is currently available only for the collocated data analyzed in this study. Our examination of ERS/N wind speed shows the bias in this partially reprocessed product is reduced to $-0.2 \mathrm{~ms}^{-1}$.

We next identify a difference in QuikSCAT and ERS/N winds that we believe is a remaining error in CMOD5.n GMF which we determine empirically as a function of wind speed and direction relative to the ERS-2 mid-beam azimuth. After applying this GMF-related correction to ERS/N winds, the global and time average wind speed difference between ERS/N and QuikSCAT winds decreases to $-0.1 \mathrm{~m} / \mathrm{s}$. Even after this correction QuikSCAT wind speed remains systematically lower (by $0.5 \mathrm{~ms}^{-1}$ ) than ERS/ $\mathrm{N}$ in regions of very cold $\mathrm{SST}<5^{\circ} \mathrm{C}$. This wind speed difference may result from temperature-dependence in the viscous damping of surface waves which has a greater impact on the shorter wavelengths observed by QuikSCAT. After applying an SST-related correction to the QuikSCAT wind speed, the global and time mean wind speed difference between ERS/N and QuikSCAT becomes negligible. 
Finally, we return to the broader issues raised by the presence of systematic errors in

345 ERS-2 winds. One outcome of our analysis is recognition that there is a significant asymmetry 346 versus the wind direction relative to the ERS-2 mid-beam azimuth. This azimuth dependence cannot be explained by errors in the GMF used for ERS-2 processing since any GMF is symmetric in azimuth. Closer examination of the backscatter coefficients for the ERS-2 beams reveals an inconsistency between the fore-beam and aft-beam, which could be responsible for this asymmetry. This finding along with an apparent wind speed bias in CMODIFR2-based product suggests the need for a complete reevaluation and reprocessing of ERS-2 scatterometer data.

Acknowledgements. This research was supported by the NASA International Ocean Vector Wind Science Team (NNXIOAD99G), and by TOSCA (Terre, Océan, Surfaces continentales, Atmosphère) project. We thank D. Croizé-Fillon, F. Paul, and J. F. Piollé and IFREMER/CERSAT for data processing support. The authors are grateful to EUMETSAT, JPL, Météo-France, NDBC, PMEL, and UK MetOffice for providing numerical, satellite, and in-situ data used in this study. 


\section{References}

Atlas, R., R. N. Hoffman, J. Ardizzone, S. M. Leidner, J. C. Jusem, D. K. Smith, and D. Gombos, 2011. A Cross-calibrated, Multiplatform Ocean Surface Wind Velocity Product for Meteorological and Oceanographic Applications. Bull. Amer. Meteor. Soc. 92, 157174. doi: 10.1175/2010BAMS2946.1

Bentamy, A., P. Queffeulou, Y. Quilfen, and K. Katsaros, 1999. Ocean surface wind fields estimated from satellite active and passive microwave instruments, IEEE T. Geosci. Rem. Sens. 37 (5), 2469-2486

Bentamy, A., K B. Katsaros, M. Alberto, W. M. Drennan, and E. B. Forde, 2002: Daily surface wind fields produced by merged satellite data. American Geophys. Union, Geophysical Monograph Series, vol. 127, 343-349.

Bentamy, A., H.-L. Ayina, P. Queffeulou, and D. Croize-Fillon, 2007. Improved Near Real Time Surface Wind Resolution over The Mediterranean Sea, Ocean Sci. 3, 259-271.

Bentamy, A., S. A. Grodsky, J. A. Carton, D. Croizé-Fillon, and B. Chapron, 2012. Matching ASCAT and QuikSCAT winds, J. Geoph. Res. 117, C02011, doi:10.1029/2011JC007479.

Bourassa, M. A., D. M. Legler, J. J. O’Brien, and S. R. Smith, 2003. SeaWinds validation with research vessels, J. Geophys Res. 108, C2, 3019.

Bourassa, M. A., A. Stoffelen, H. Bonekamp, P. Chang, D. B. Chelton, J. Courtney, and Coauthors, 2009: Proceedings of OceanObs’09: Sustained Ocean Observations and Information for Society. 21-25 September, Venice, Italy. (http://www.oceanobs09.net/proceedings/cwp/Bourassa-OceanObs09.cwp.08.pdf )

Bourlès, B., R. Lumpkin, M. J. McPhaden, F. Hernandez, P. Nobre, E. Campos, L. Yu, S. Planton, A. Busalacchi, A. D. Moura, J. Servain, and J. Trotte 2008. The Pirata 
Program: History, Accomplishments, and Future Directions. Bull. Amer. Meteor. Soc. 89, 1111-1125. doi: 10.1175/2008BAMS2462.1

Center for Satellite Exploitation and Research (CERSAT), 1994. WNF products - User manual, IFREMER/CERSAT, C2-MUT-W-01-IF, pp. 86, available at ( http://cersat.ifremer.fr/content/download/2414/16735/file/mutw01.pdf ).

Crapolicchio, R., G. De Chiara A. Paciucci, and P. Lecomte, 2007. The ERS-2 scatterometer: instrument and data performances assessment since the beginning of the mission. Proc. ‘Envisat Symposium 2007’, Montreux, Switzerland 23-27 April 2007 (ESA SP-636, July 2007).

Crosby, D.S., L.C. Breaker, and W.H. Gemmill, 1993. A proposed definition for vector correlation in geophysics: theory and application. J. Atm. Ocean. Techn. 10, 355 - 367.

De Chiara, G., and H. Hersbach, 2009. ERS-2 scatterometer cycle report. ESA publication. http://earth.esrin.esa.it/pcs/ers/scatt/reports/pcs cyclic/wscatt rep 144.pdf. pp. 63.

Donelan, M. A., and W. J. Pierson, 1987. Radar scattering and equilibrium ranges in windgenerated waves with application to scatterometry. J. Geophys. Res. 92, 4971-5029. doi:10.1029/JC092iC05p04971

Ebuchi, N., H. C. Graber, and M. J. Caruso, 2002. Evaluation of wind vectors observed by QuikSCAT/SeaWinds using ocean buoy data. J. Atmos. Ocean. Techn. 19, 2049-2069.

Fairall, C.W., E.F. Bradley, J.E. Hare, A.A. Grachev, and J.B. Edson, 2003. Bulk Parameterization of Air-Sea Fluxes: Updates and Verification for the COARE Algorithm, J. Clim. 16, 571-591.

Freilich, M.H. 1997. Validation of vector magnitude data sets: Effects of random component errors. J. Atmos. Ocean. Tech. 14, 695-703. 
Grodsky, S. A., V. N. Kudryavtsev, A. Bentamy, J. A. Carton, and B. Chapron, 2012. Does direct impact of SST on short wind waves matter for scatterometry?, Geophys. Res. Lett. 39, L12602, DOI: 10.1029/2012GL052091.

Hersbach, H., 2010, Comparison of C-Band Scatterometer CMOD5.N Equivalent Neutral Winds with ECMWF, J. Atm. Ocean. Techn. 2010, 27, 721-736

Jet Propulsion Laboratory (JPL), 2006. QuikSCAT Science Data Product User's Manual Overview \& Geophysical Data Products, ftp://podaacftp.jpl.nasa.gov/allData/quikscat/L2B/docs/QSUG v3.pdf

McPhaden, M. J., A. J. Busalacchi, R. Cheney, J-R. Donguy, K. S. Gage, D. Halpern, M. Ji, P. Julian, G. Meyers, G. T. Mitchum, P. P. Niiler, J. Picaut, R. W. Reynolds, N. Smith, and K. Takeuchi, 1998. The Tropical Ocean-Global Atmosphere observing system: A decade of progress, J. Geophys. Res. 103(C7), 14,169-14,240, doi:10.1029/97JC02906.

Meindl, E.A., and G.D. Hamilton, 1992. Programs of the National Data Buoy Center, Bull. Amer. Meteor. Soc. 4, 984-993.

Quilfen, Y., 1995. ERS-1 off-line wind scatterometer products. IFREMER Tech. Rep., 75 pp.

Quilfen Y., Chapron, and B., Vandemark, D., 2001. The ERS Scatterometer Wind Measurement Accuracy: Evidence of Seasonal and Regional Biases, J. Atmos. Ocean. Techn. 18, 10, 1684-1697.

Quilfen, Y., B. Chapron, F. Collard, D. Vandemark, 2004. Relationship between ERS Scatterometer Measurement and Integrated Wind and Wave Parameters. J. Atmos. Ocean. Techn.., 21, 368-373.

Tournadre, J., and Y. Quilfen , 2003. Impact of rain cell on scatterometer data: 1. Theory and modeling, J. Geophys. Res. 108, 3225, doi:10.1029/2002JC001428, C7. 
429 Tournadre, J., and Y. Quilfen, 2005. Impact of rain cell on scatterometer data: 2. Correction of $430 \quad$ Seawinds measured backscatter and wind and rain flagging, J. Geophys. Res. 110, $431 \quad$ C07023, doi:10.1029/2004JC002766.

432 Weissman, D. E., M. A. Bourassa, and J. Tongue, 2002. Effects of Rain Rate and Wind 433 Magnitude on SeaWinds Scatterometer Wind Speed Errors. J. Atmos. Ocean. Techn. 19, 434 738-746. doi: 10.1175/1520-0426(2002)019<0738:EORRAW>2.0.CO;2

435 Wentz, F.J, L. Ricciardulli, K. Hilburn, and C. Mears, 2007. How much more rain will global 436 warming bring? Science 317, 233-235, doi:10.1126/science.1140746. 
Table 1: Statistics of differences between NDBC buoy hourly winds and collocated scatterometer winds with number of valid quality control flags (see text): record length, bias, standard deviation, and correlation. Values determined only using data from the period of ERS-2/QuikSCAT overlap are in parentheses. Statistics for ERS-2 using CMOD5.n are also included.

\begin{tabular}{|c|c|c|c|}
\hline & & Wind Speed & Wind Direction \\
\hline \multirow{4}{*}{ ERS-2 (CMOD2IFR) } & Length & \multicolumn{2}{|l|}{ 9985(3659) } \\
\hline & Bias & $0.66(0.80)$ & $-5(-4)$ \\
\hline & Std & $1.21(1.19)$ & 19(19) \\
\hline & Cor & $0.94(0.94)$ & $1.80(1.79)$ \\
\hline \multirow{4}{*}{ QuikSCAT } & Length & \multicolumn{2}{|l|}{$57714(7720)$} \\
\hline & Bias & $0.01(0.03)$ & $-3(-5)$ \\
\hline & Std & $1.03(1.02)$ & $16(16)$ \\
\hline & Cor & $0.95(0.95)$ & $1.87(1.86)$ \\
\hline \multirow{4}{*}{ ERS/N (CMOD5.n) } & Length & \multicolumn{2}{|l|}{$9985(3659)$} \\
\hline & Bias & $0.05(-0.07)$ & $-5(-4)$ \\
\hline & Std & $1.4(1.35)$ & 19(19) \\
\hline & Cor & $0.9(0.91)$ & $1.80(1.79)$ \\
\hline
\end{tabular}



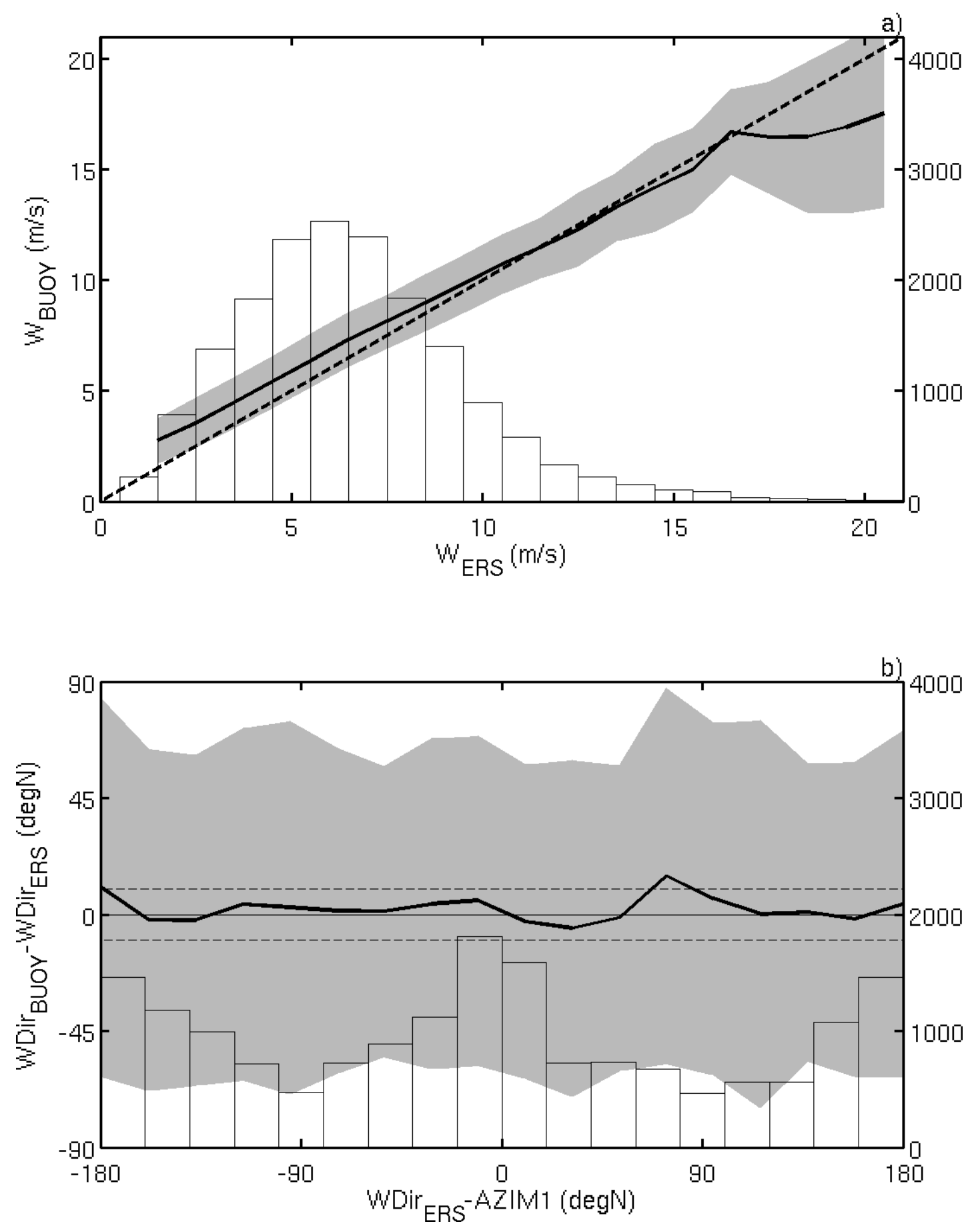

Figure 1. (a) 10m equivalent neutral buoy wind speed from NDBC and TAO moorings versus ERS-2 wind speed (left-hand axis). Histogram of $W_{E R S}$ (right-hand axis). (b)

441 Difference between buoy and ERS-2 wind directions versus ERS-2 wind direction relative to 442 the mid-beam azimuth (WDir ${ }_{E R S}-A Z I M 1$ ). Dashed lines indicate $\pm 10^{\circ}$. Histogram of ERS-2 443 relative wind direction is also shown (right-hand axis). Azimuth angles are calculated 444 counterclockwise from north $(\mathrm{degN})$. $W D i r_{E R S}-A Z I M 1=0$ corresponds to ERS-2 mid-beam 445 looking along the wind vector. Gray shading is \pm STD in each bin. 

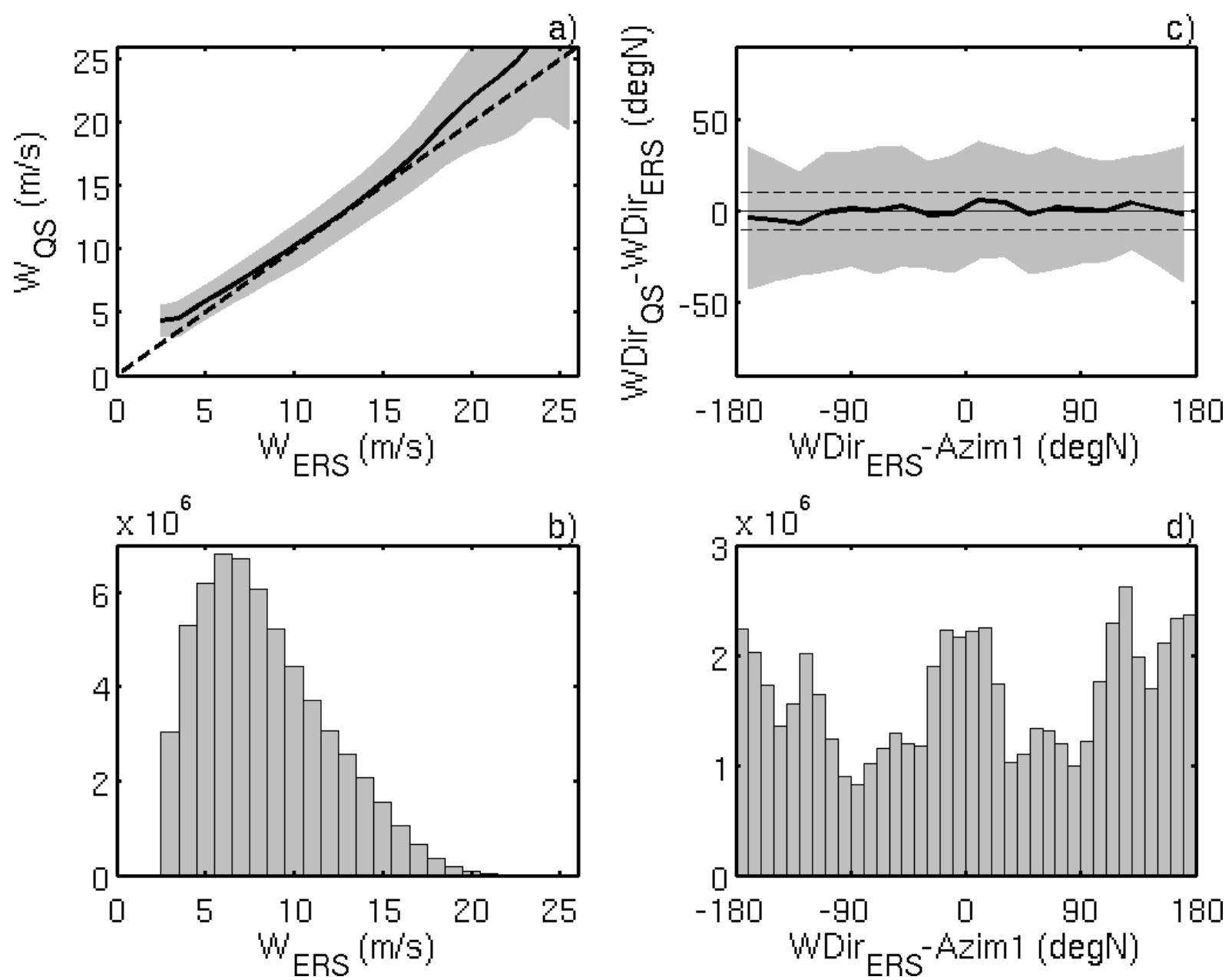

Figure 2. Gross comparison of collocated QuikSCAT (QS) and ERS-2 winds. (a) QS wind speed $\left(W_{Q S}\right)$ versus ERS-2 wind speed $1 \mathrm{~m} / \mathrm{s}$ bins $\left(W_{E R S}\right)$. Shading shows \pm 1 STD of $W_{Q S}$ in each bin. (b) Histogram of $W_{E R S}$. (c) Difference between QS and ERS wind directions binned $10^{\circ}$ in ERS-2 wind direction relative to the mid-beam azimuth. Dashed lines indicate $\pm 10^{\circ}$. Gray shading shows \pm 1 STD. (d) Histogram of the relative ERS-2 wind direction. Azimuth angles are calculated counterclockwise from north (degN). Zero relative wind direction in c) and d) corresponds to ERS-2 mid-beam looking along the wind vector. 



457 Figure 3. (a) Time mean difference between collocated QS and ERS-2 wind speed

458 ( $\left.W_{Q S}-W_{E R S}\right)$, (b) STD of the difference, and (c) temporal correlation of instantaneous

459 collocated wind speeds at each bin. QuikSCAT rain flag and MRP $<0.5$ are both applied. 

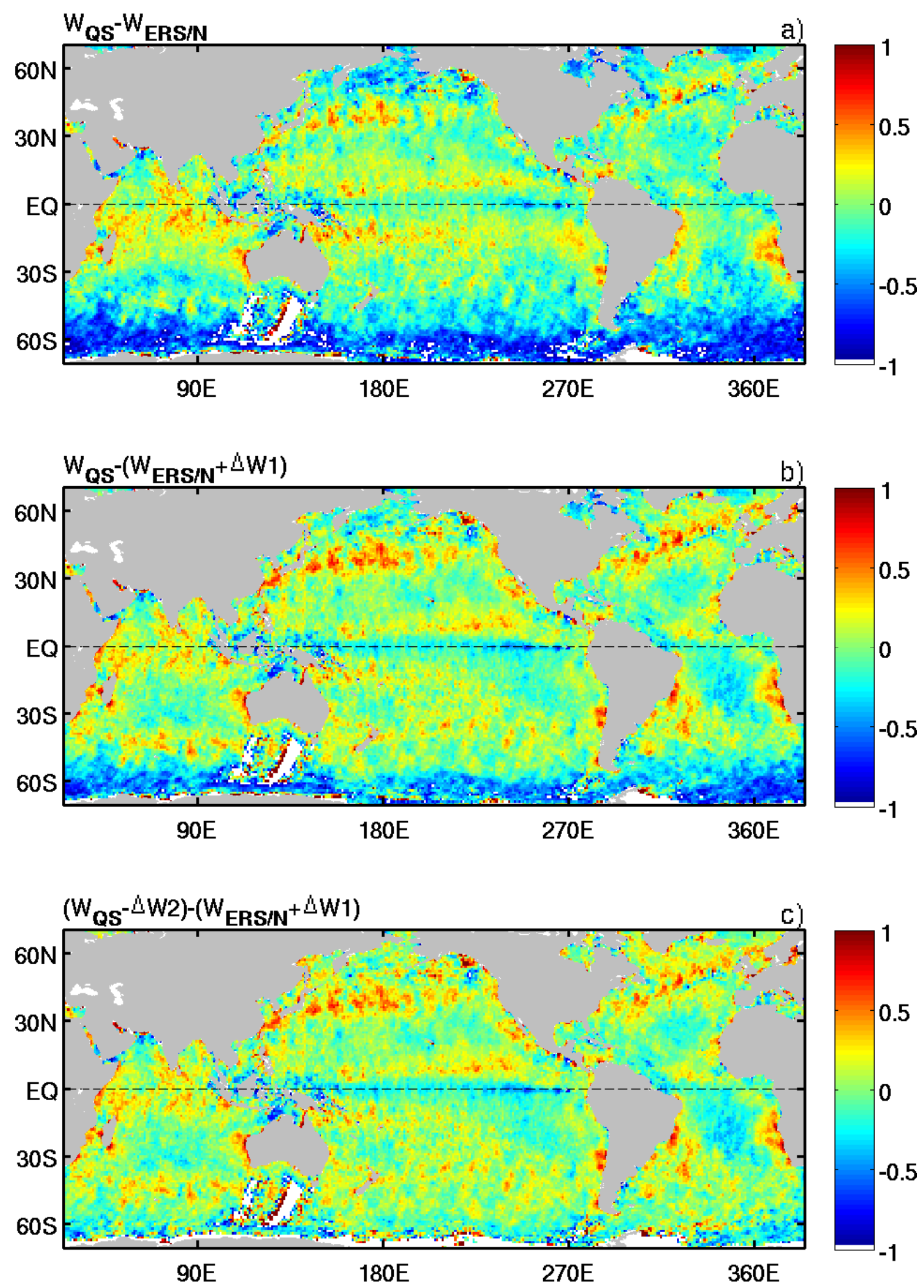

Figure 4. Time mean difference between collocated QuikSCAT and ERS-2 wind speeds. (a) ERS-2 wind partially reprocessed with CMOD5.n (ERS/N). (b) ERS/N wind corrected for GMF dependence $\left[W_{E R S / N}+\Delta W 1\left(W_{E R S / N}, \chi\right)\right]$. (c) ERS/N wind corrected for GMF dependence $\triangle W 1$ and QS winds corrected for SST dependence $\left[W_{Q S}-\Delta W 2\left(W_{Q S}, S S T\right)\right]$. 

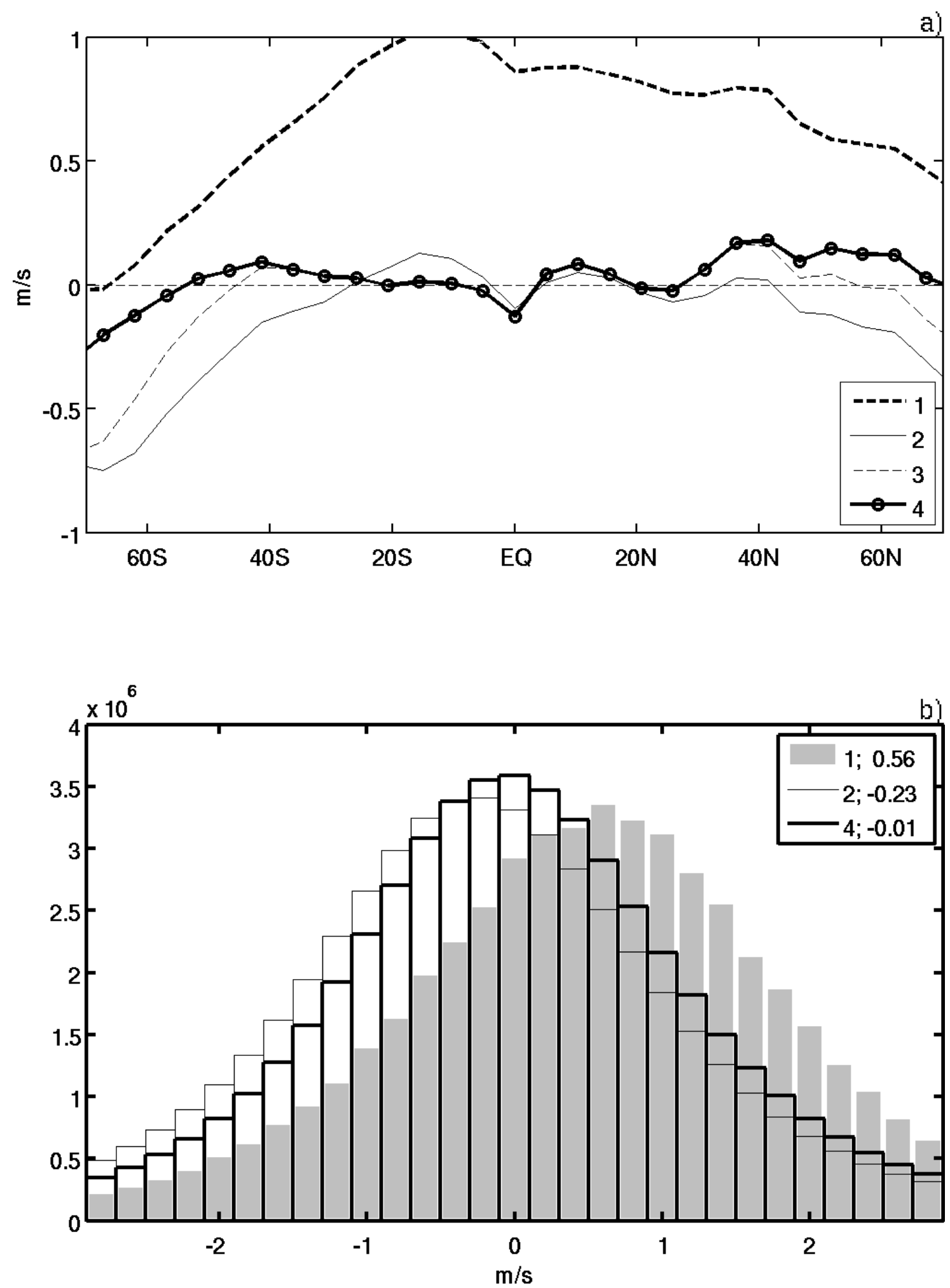

Figure 5. (a) Zonally averaged collocated wind speed difference for four cases: (1) CMODIFR2-based ERS-2 winds $\left(W_{Q S}-W_{E R S}\right)$,

(2) CMOD5.n-based ERS-2 winds

(3) after applying

GMF-related correction to ERS-2 $\left(W_{Q S}-\left(W_{E R S / N}+\Delta W 1\right)\right)$ (4) after applying GMF-related correction to ERS-2 and SSTrelated correction to QuikSCAT, $\left(W_{Q S}-\Delta W 2\right)-\left(W_{E R S / N}+\Delta W 1\right)$.

(b) Histogram of collocated wind speed difference fro the same cases. Numbers are median wind speed differences in $\mathrm{m} / \mathrm{s}$. 

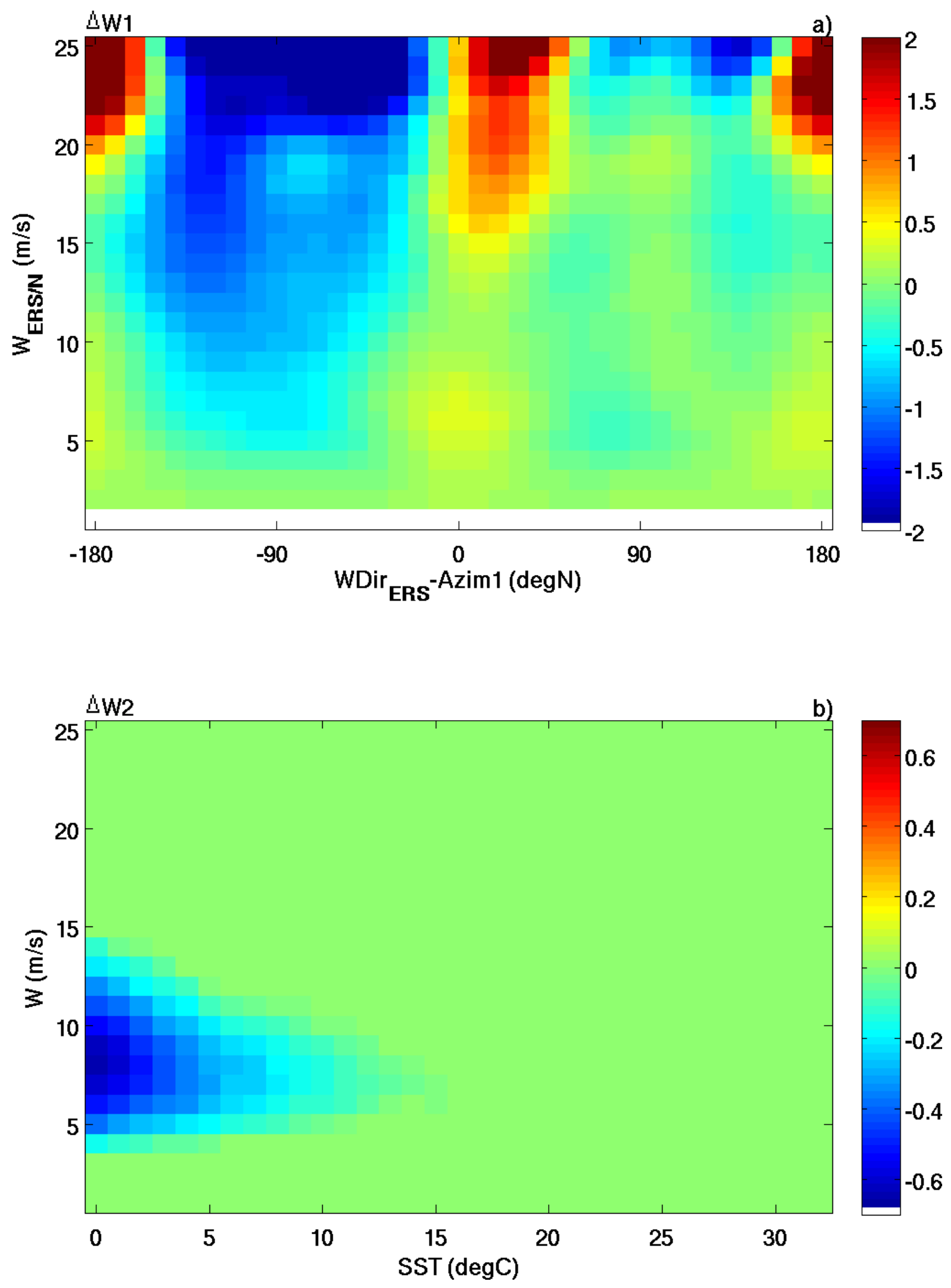

Figure 6. (a) Wind speed difference ( $\triangle W 1$ ) between collocated QuikSCAT and ERS/N (ERS2 reprocessed with CMOD5.n) plotted as a function of wind speed and wind direction relative 477 to the mid-beam azimuth. (b) $\triangle W 2$, the SST-related correction for QuikSCAT wind speed 478 (adopted from Bentamy et al., 2012). 

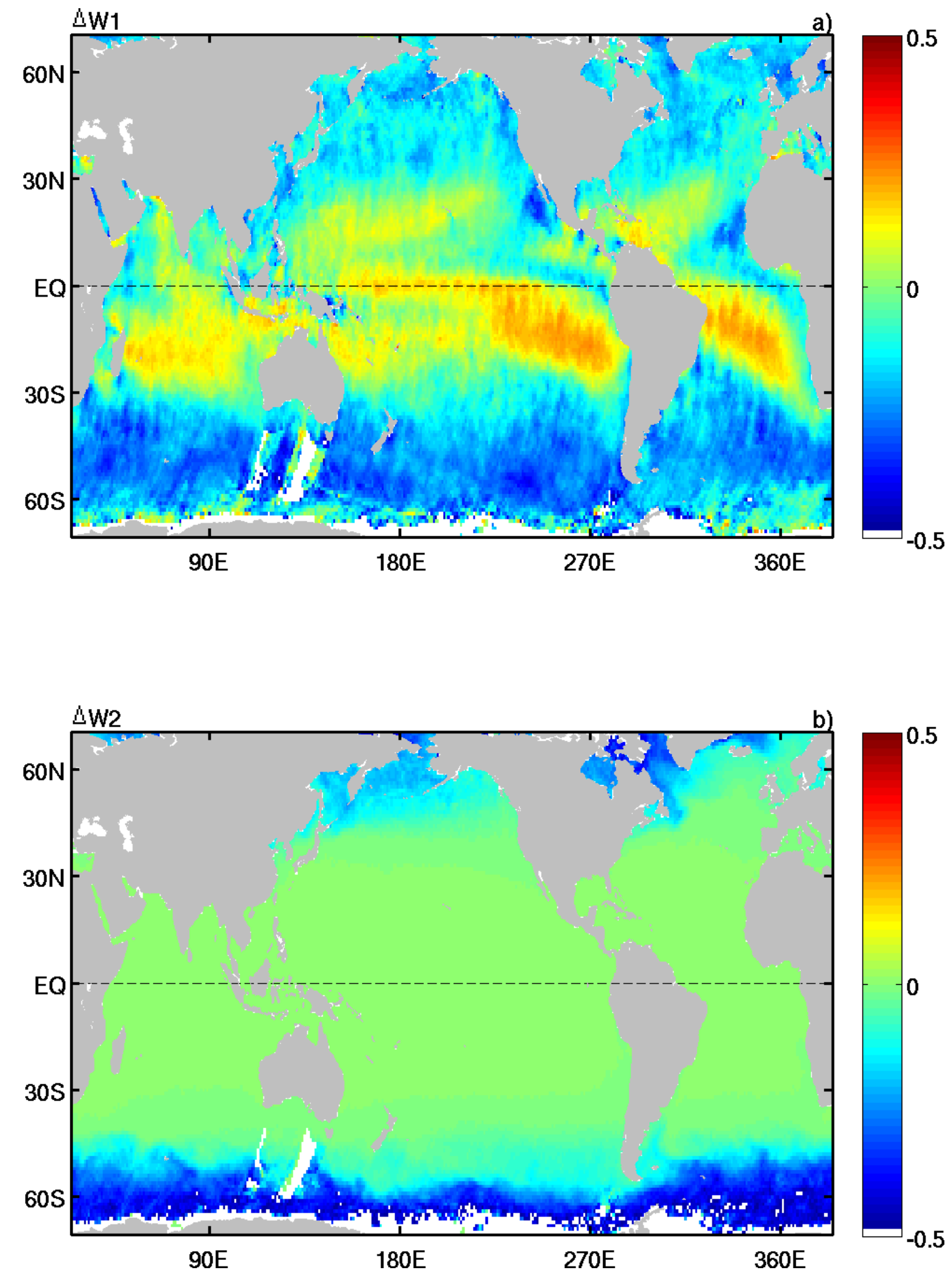

Figure 7. Time mean (a) GMF-related wind speed correction for ERS/N ( $\triangle W 1$ ), (b) SST482 related wind speed correction for QuikSCAT ( $\triangle W 2$ ) applied to all collocated differences. 


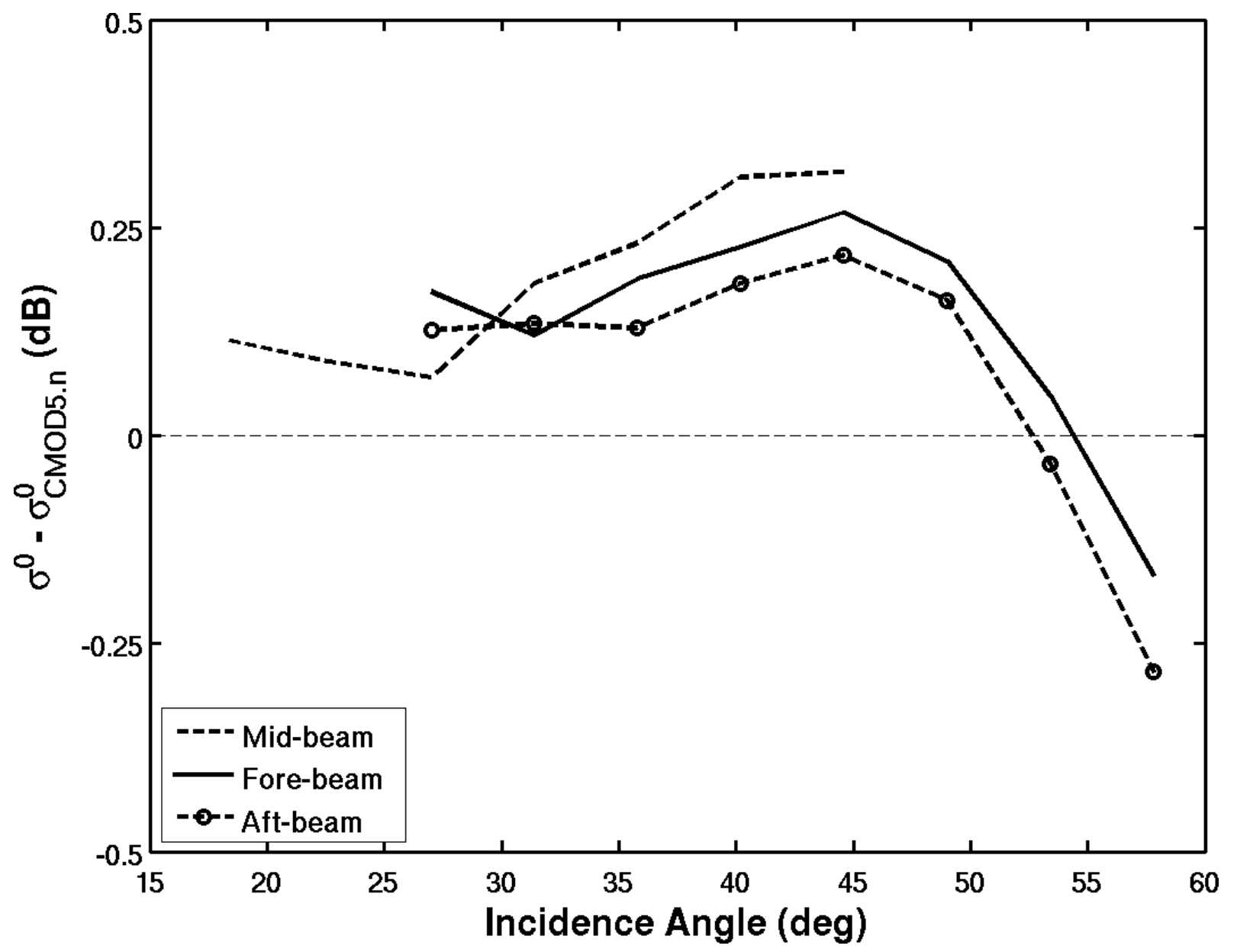

Figure 8. Observed radar backscatter $\left(\sigma^{0}\right)$ minus backscatter simulated with the corrected 